\title{
Consecuencias de las medidas adoptadas en México a raíz del coronavirus. Análisis de una posible responsabilidad
}

\section{Consequences of the measures taken in México in the root of the coronavirus. Analysis of possible liability}

\author{
SUSANA MARTÍNEZ NAVA
} Miguel ÁNGel Veloz Romo

$0^{\circ}$ lus Comitiãlis / Año 3, Número 6 / julio - diciembre 2020 / pp. 239-260 / ISSN: 2594-1356 Recepción: 20 de julio del 2020 / Aceptación: 25 de octubre de 2020

Resumen: La pandemia COVID-19 ha demostrado la imposibilidad de los Estados para brindar seguridad al no garantizar que las personas se queden en casa, derivado de la falta de generación de mecanismos que permitan brindarle a la población un mínimo vital al momento de confinarla, así como por la carencia de opciones viables al sector económico, formal o informal para enfrentar la crisis económica acelerada por la pandemia. Todo ello lleva a cuestionar hasta qué punto el Estado mexicano es responsable de los daños económicos que se producen con las medidas adoptadas para contrarrestar la pandemia.

Palabras clave: Seguridad, derechos humanos, daños y responsabilidad del Estado.

Abstract: The COVID-19 pandemic has demonstrated the impossibility of States to provide security by not guaranteeing that people stay at home, derived from the lack of generation of mechanisms that allow providing the population with a vital minimum at the time of confining them, as well as due to the lack of viable options for the economic, formal or informal sector to face the economic crisis accelerated by the pandemic. All this leads to questioning to what extent the Mexican State is responsible for the economic damages that occur with the measures adopted to counter the pandemic.

Key words: Security, human rights, damages and responsibility of the State.

https://orcid.org/0000-0001-7230-3439. / Correo electrónico: susymn9@yahoo.es

${ }^{1}$ Doctora en Derecho. Profesora investigadora de tiempo completo en la Universidad de Guanajuato. México. Miembro del Sistema Nacional de Investigadores nivel candidata a investigadora nacional.

https://orcid.org/0000-0001-8369-0032. / Correo electrónico: angel.veloz@edu.uaa.mx

${ }^{2}$ Doctor en Derecho por la Universidad Autónoma de Nayarit. Profesor Investigador de la Universidad Autónoma de Aguascalientes. México. Candidato a Investigador Nacional por parte del Sistema Nacional de Investigadores del CONACYT. 


\section{INTRODUCCIÓN}

La situación que priva en México y en el mundo por la crisis sanitaria derivada de la enfermedad por COVID-19, generó que los gobiernos de los Estados ante el desconocimiento real de las características y formas de transmisión, establecieran medidas de protección del derecho a la salud, sin importar las consecuencias que las mismas traerían con relación a otros derechos humanos, llegando en algunos casos al grado de declarar, de facto, estados de emergencia o excepción.

Ante ello, se hace necesario un análisis de qué situación debe prevalecer y de la pertinencia o no de las medidas adoptadas, pues generaron y siguen generando un disfrute parcial de los derechos humanos de los gobernados (restricción) o inclusive, una imposibilidad total del disfrute de los mismos (suspensión).

Lo anterior tiene relevancia en razón de que los derechos humanos, en un Estado Constitucional de Derecho, deben respetarse y garantizarse en todo momento, ya que una emergencia sanitaria o cualquier otro fenómeno que altere la vida en sociedad no debe trastocar, más allá de lo que lleva implícito, el ejercicio y disfrute de los derechos. Por el contrario, es especialmente trascendente que el Estado se constituya en garante de las facultades necesarias para que los gobernados logren, ante la incertidumbre de una emergencia, tener la certeza de que sus derechos civiles y políticos, económicos, sociales y culturales estarán a salvo.

Las estrategias que son adoptadas sin someterse a un tamizaje de derechos humanos, no tienen otro resultado más que violentarlos. El objetivo de este trabajo es poner de manifiesto dos cosas en especial: qué situación prevalece, de acuerdo al relato del Estado mexicano, y si es posible determinar consecuencias o responsabilidades por un mal posicionamiento de las políticas emergentes para responder a este escenario.

Adicionalmente, se lleva a cabo un ejercicio comparativo utilizando una tabla que permita identificar más fácilmente las consecuencias de haber adoptado las decisiones contenidas en los Acuerdos emitidos por distintas autoridades, usando para ello categorías relativas a los efectos ocasionados y los derechos humanos involucrados.

\section{LA SITUACIÓN QUE PARA EFECTOS JURÍDICOS SE VIVE EN MÉXICO}

Resulta fundamental establecer, en términos jurídicos, la situación que priva durante la pandemia ocasionada por el COVID-19, toda vez que con base en ella se determirán 
la legalidad y legitimidad de las medidas adoptadas y las consecuencias de estas, sobre todo en lo que corresponde a la restricción de derechos humanos y garantías, así como el impacto que esto puede acarrear en materia de seguridad humana en México.

A consecuencia de la situación internacional frente a la enfermedad por COVID-19, fue declarada por la Organización Mundial de la Salud una emergencia de salud pública de preocupación internacional el 30 de enero de 2020 (OMS, 2020). La caracterización de la pandemia significa que la epidemia se ha extendido por varios países, continentes o todo el mundo, y que afecta a un gran número de personas (OPS, 2020).

A continuación, se analiza lo dispuesto a nivel Constitucional, legal y reglamentario, así como los acuerdos dictados por el Consejo de Salubridad para hacer frente a este acontecimiento por ser el marco normativo que ha servido de base para entender, como ya se dijo, ante qué situación jurídica nos encontramos.

Las normas constitucionales aplicables a este evento son el artículo $4^{\circ}$; 73, fracción XVI, bases primera, segunda y tercera; estas disposiciones reconocen, por una parte, el derecho a la protección de la salud, la facultad del Estado de establecer la forma en la que los gobernados tendrán acceso a los servicios de salud, así como los órganos a cargo en los cuales recaerá esta función y su concurrencia, asimismo se establece como autoridad sanitaria al Consejo de Salubridad General para que en este caso dicte las medidas preventivas indispensables, las cuales son obligatorias para todas las autoridades administrativas del país.

Ahora bien, la Ley General de Salud (2019) define la composición del Consejo de Salubridad General y algunas de sus funciones, la cuales se desarrollan de manera pormenorizada en el Reglamento Interno de este órgano; también es necesario señalar que la Ley en comento distribuye las competencias en materia de salud que corresponde a la federación y a los estados, y prevé la obligación de notificar de manera inmediata a la Secretaría de Salud o a la autoridad más cercana cuando se presente cualquier enfermedad en forma de brote o epidemia.

En ese último caso, para hacer frente a las epidemias, las autoridades sanitarias competentes están facultadas para utilizar como elementos auxiliares los recursos médicos y de asistencia social del sector público, social y privado que existan en la región; también señala que las autoridades sanitarias podrán ordenar la clausura de temporal de locales o centros de reunión de cualquier índole, por causa de una epidemia.

En este contexto normativo, el Consejo de Salubridad General emitió los siguientes acuerdos:

- Acuerdo del 23 de marzo por el que el Consejo General de Salubridad reconoce la epidemia por el virus SARS-CoV-2 en México como una enfermedad grave de atención prioritaria, por ello se establecen las actividades de preparación y respuesta ante dicha pandemia (2020). 
Además de reconocer estas características a la epidemia, sanciona las medidas de preparación, prevención y control, que, según el acuerdo, se diseñarán, coordinarán y supervisarán por la Secretaría de Salud, para ser implementadas por los tres poderes, en los tres niveles de gobierno, así como el sector social y privado; se exhorta a las entidades a llevar a cabo planes para la reconversión hospitalaria y la expansión de su capacidad para la atención oportuna a la epidemia.

- Acuerdo del 24 de marzo del 2020, emitido por la Secretaría de Salud, establece las medidas preventivas que se deberán implementar para la mitigación y control de riesgos para la salud que implica la enfermedad por el virus Covid-19 (2020).

- Acuerdo del 26 de marzo del 2020, emitido por la Secretaría de Salud, donde se establece la suspensión de plazos y términos legales en la práctica de actuaciones y diligencias en los procedimientos administrativos que se desarrollan ante la Secretaría de Salud, sus unidades administrativas y organismos desconcentrados (2020).

- Acuerdo del 26 de marzo del 2020, donde el Consejo de Salubridad General señala los días inhábiles del 26 de marzo al 19 de abril de 2020 para la realización de trámites administrativos (2020).

Para efectos de ilustrar mejor lo que se quiere evidenciar, se citan algunas partes del Acuerdo:

Las autoridades civiles, militares y los particulares, así como las dependencias y entidades de los tres órdenes de gobierno, estarán obligadas a la instrumentación de las medidas preventivas contra la enfermedad por el virus SARS-CoV2 (COVID-19), a que se refiere el primer párrafo de este artículo.

Para efectos de este Acuerdo se entenderá por medidas preventivas, aquellas intervenciones comunitarias definidas en la "Jornada Nacional de Sana Distancia", que tienen como objetivo el distanciamiento social para la mitigación de la transmisión poblacional de virus SARS-CoV2 (COVID-19), disminuyendo así el número de contagios de persona a persona y por ende el de propagación de la enfermedad, con especial énfasis en grupos vulnerables, permitiendo además que la carga de enfermedad esperada no se concentre en unidades de tiempo reducidas, con el subsecuente beneficio de garantizar el acceso a la atención médica hospitalaria para los casos graves.

También se especifican las medidas preventivas del sector público, privado y social que prevén la necesidad de que sectores vulnerables de la población, por cuestiones de salud, no concurran a laborar; la suspensión de actividades escolares y de aquellas involucren la concentración física, tránsito o desplazamiento de personas; la implementación de planes para dar continuidad a actividades esenciales y realizar la suspensión de eventos masivos, reuniones y congregaciones de más de 100 personas, 
entre las que sobresalen el cumplimiento de las medidas básicas de higiene y la sana distancia.

- Decreto del 27 de marzo del 2020, emitido por el titular del poder Ejecutivo Federal, por el que se declaran acciones extraordinarias en las regiones afectadas de todo el territorio nacional en materia de salubridad general para combatir la enfermedad de atención prioritaria generada por el virus Covid-19 (2020).

- Acuerdo del 30 de marzo de 2020, emitido por el Consejo de Salubridad General, por el cual se declara como emergencia sanitaria a la epidemia de enfermedad generada por el virus Covid-19 (2020).

- Acuerdo del 30 de marzo del 2020, emitido por la Secretaría de Salud, por el cual se establecen acciones extraordinarias para atender la emergencia sanitaria por causa de fuerza mayor generada por el virus Covid-19 (2020).

Este acuerdo trajo como resultado que las empresas que no desarrollaran actividades esenciales, les fuera aplicable lo contenido en el artículo 427, fracción I de la Ley Federal del Trabajo (2019) que prevé una suspensión temporal de las relaciones de trabajo; esta medida ocasiona que la empresa esté obligada al pago de salarios íntegros mientras dure la suspensión, contrario a lo que se esperaba, que era el reconocimiento de una contingencia sanitaria que posibilitara a los patrones el pago de una indemnización equivalente a un día de salario mínimo general, vigente por el tiempo que dure la suspensión, sin que excediera de un mes.

Aunado a esto, no se otorgaron beneficios fiscales que están considerados en el artículo 39 del Código Fiscal de la Federación y que son una potestad del ejecutivo federal en caso de epidemias.

- Acuerdo del 31 de marzo de 2020, emitido por la Secretaría de Salud, en el que se establecen los lineamientos técnicos relacionados con las actividades de los sectores fundamentales de la economía; así como las necesarias para la conservación, mantenimiento y reparación de la infraestructura crítica para asegurar la producción y distribución de servicios indispensables (2020).

De todas las disposiciones emitidas en los acuerdos y decretos, las últimas tres son las que mayor afectación representan a las actividades sociales, económicas y jurídicas, ya que como se expresó, no se brindaron opciones a las empresas para evitar que su liquidez se pusiera en peligro, provocando a su vez la incapacidad para sostener las relaciones laborales, lo que ha traído como resultado que la Tasa de Participación Económica en abril fuera del 47.5\% respecto a la población de 15 años y más, cifra inferior en $12.3 \%$ que la reportada en marzo, lo que significa que de 57 millones se pasó a 45 millones de personas económicamente activas, es decir, 12 millones de personas que se encontraron con una suspensión laboral sin percepción de ingresos y sin la certeza de mantener la relación laboral (INEGI, 2020). 
Por lo que se ha abordado y para concretar la situación jurídica que prevalece es incierta; la Jornada Nacional de Sana Distancia concluyó el 30 de mayo sin que los contagios fueran en descenso, por el contrario, no se alcanzaba todavía el punto máximo de contagios y el ascenso apenas comenzaba, con esto se dio paso a un sistema de semaforización (Acuerdo del 14 de mayo, 2020), el cual coloca a los estados y municipios en colores que corresponden a su estatus de contagio para la reapertura de las actividades económicas; sin embargo la categorización de los estados conforme a este semáforo parte de un número acumulado de casos que no tiene un fundamento, es decir, no se toman en cuenta las características de la extensión territorial, la concentración de población, capacidad de los servicios de salud o alguna otra variable que pudiera impactar en la determinación de cómo hacer frente a la pandemia.

A la fecha en la que se escribe este texto los casos de contagios registrados por el gobierno de México han alcanzado casi los 400,000 y se han suscitado más de 47,000 defunciones (Covid-19 México, 2020); cabe señalar que los estimados son superiores, sin embargo, las actividades económicas en gran parte del país han vuelto a la "nueva normalidad", misma que es un eufemismo para designar al contexto bajo el cual debemos relacionarnos y convivir para evitar más contagios.

Lo que la "nueva normalidad" pone de manifiesto es que estamos ante la omisión del Estado de garantizar seguridad: ni jurídica, ni humana; las estrategias de salud parecen depender únicamente de la sociedad; la economía no puede recuperarse mientras no se controlen los contagios, así que el empleo y el desarrollo no pueden tener lugar mientras no se garantice la salud; la seguridad jurídica tampoco es viable mientras no se determine de manera clara la situación que prevalece; frente a este escenario lo único seguro es la incertidumbre, que como ya sabemos es un contexto propicio para la violación de derechos fundamentales.

El contexto generado, en parte por la emergencia sanitaria y por la respuesta del Estado mexicano, también ha revelado una falta de coordinación entre los poderes, así como entre los niveles de gobierno, ya que incluso dentro de la propia administración pública, pareciera que hubo secretarías que se adelantaron a los posicionamientos del Consejo de salubridad, como lo fue la de Educación, al emitir el Acuerdo número 02/03/20 por el que se suspenden las clases en las escuelas de educación preescolar, primaria, secundaria, normal y demás para la formación de maestros de educación básica del sistema educativo nacional, así como aquellas de los tipos medio superior y superior dependientes de la secretaría de educación pública y en este mismo rubro.

En lo que corresponde a la Suprema Corte de Justicia de la Nación esta decidió suspender sus labores a partir del 18 de marzo, dejando a salvo las controversias constitucionales urgentes y en varios estados, los poderes judiciales decidieron adelantarse a la federación suspendiendo actividades desde la misma fecha, como lo fue el Poder Judicial de la Ciudad de México (Acuerdo 39-14, 2020), entre otros.

En el sector educativo de nivel superior, en Monterrey, instituciones como el Colegio Americano, la Universidad de Monterrey y el Instituto Tecnológico de Estudios Superiores de Monterrey suspendieron labores desde el 12 y 13 de marzo como 
medidas preventivas y así siguieron su ejemplo la Universidad de Guadalajara, que lo hizo a partir del 17 de marzo, así como la Universidad Nacional Autónoma de México, la Universidad Autónoma de Metropolitana, la Iberoamericana, la Panamericana de la Ciudad de México, Anáhuac, entre muchas otras.

$\mathrm{Al}$ analizar lo expuesto en el marco jurídico al que se ha hecho referencia, para determinar la situación jurídica en la que se encuentra México es necesario precisar que, conforme a los Acuerdos emitidos por el Consejo de Salubridad y el decreto del poder ejecutivo, estamos frente a una emergencia sanitaria por causa de fuerza mayor debido a la enfermedad por COVID-19. Como se puede advertir de la simple lectura de los Acuerdos, el confinamiento es voluntario y las entidades federativas podrán decretar otras medidas tendientes a evitar la propagación de esta enfermedad.

Con esto se afirma que no se aplicó, ni podría aplicarse el supuesto contenido en el artículo 29 constitucional, que hace referencia a un estado de excepción, sin embargo, en algunas entidades federativas y municipios se impusieron toques de queda $^{3}$, cierre de sus territorios, patrullaje de los elementos de la Guardia Nacional y Policía Preventiva para conminar a las personas a no transitar las calles o llevar a cabo reuniones, incluso, la suspensión de comercios y el programa para evitar la movilidad vehicular denominado" Hoy no circula ${ }^{4}$, con motivo del cumplimiento de las medidas decretadas por la "Jornada Nacional de Sana Distancia."

\section{LEGITIMACIÓN DE LA RESTRICCIÓN O SUSPENSIÓN DE DERECHOS HUMANOS A CAUSA DE LA PANDEMIA}

Con base en la descripción del marco constitucional, legal y de las disposiciones dictadas por las autoridades de salud, se plantea $¿ E l$ estado decretado amerita de manera legítima la suspensión de derechos humanos o garantías bajo la justificación de hacer frente a la pandemia?, ¿cuáles serían los derechos o garantías que pudieran verse afectados?, ¿hasta qué grado tendría lugar su limitación y la temporalidad considerada para esos efectos?

La respuesta es fácil si se piensa sólo en términos sobre hacer necesario para evitar la propagación de la enfermedad, sin duda esto último es importante, pero también es igualmente importante evitar la afectación de otros derechos e incluso del mismo derecho a la salud; un ejemplo es la salud mental, que se ha visto seriamente afectada por el confinamiento, por la pérdida de empleos, por el miedo que se ha infundido a raíz de la pandemia, y además están las libertades, que se han limitado sin tener la mejor evidencia científica de que su restricción es la única manera o la mejor manera de salvaguardar la salud de la población.

\footnotetext{
${ }^{3}$ Municipios de Guerrero, Jalisco, Michoacán, Zacatecas, Baja California, Nuevo León, Nayarit, Estado México, Veracruz y Oaxaca.

${ }^{4}$ Por ejemplo, en el estado de Zacatecas se implementó el Programa para reducir la movilidad vehicular: Hoy no circula.
} 
En virtud de esa respuesta, se hace necesario hacer frente a la parte difícil, la que requiere equilibrar todos los derechos para tomar las mejores decisiones para los gobernados, las que implican un esfuerzo mayor de parte del gobierno en el sentido de sopesar los alcances de las decisiones en el terreno económico, social, jurídico, político; para que se garantice el menor impacto posible frente al fenómeno que se experimenta, pero también en cuanto a las restricciones que se deban aplicar.

Sin embargo, es notorio que el gobierno federal ha dejado el peso del cumplimiento de las medidas de la "Jornada Nacional de Sana Distancia" a cargo de los estados y municipios porque son estos gobiernos los encargados de las medidas administrativas, para la ejecución de las prevenciones contenidas en los acuerdos, es decir, son los que deben disuadir a los ciudadanos de que se queden en casa, que no salgan a trabajar, ni a reunirse con otras personas, a no hacer las actividades que cotidianamente hacen por las exigencias de la vida, que al vivir societariamente, además de requerir la satisfacción de necesidades de primer orden, también generamos vínculos afectivos que precisamos mantener.

De este modo, los gobiernos locales y de mayor proximidad a la gente, como lo son los gobiernos municipales, construyen sus propias estrategias sin contar con muchas herramientas, es decir, sin tener muchas opciones para evitar que la sociedad no se movilice, que no actúe como normalmente lo hace, que es a través del trabajo, la recreación, la interacción con otras personas, ya que con ello podría propagar la enfermedad COVID-19, dado lo que se conoce de su naturaleza y forma de contagio.

Es en este momento en que a los gobiernos de los estados se les comienza a presionar con la exhibición pública a nivel nacional, a través de las conferencias de prensa transmitidas para efectos de informar al país de la aparición de casos, en qué lugares y cómo se dan las fases del modelo epidemiológico, que, dicho sea de paso, no se sabe quién lo eligió y con base en qué.

Este espacio sirve para evidenciar si los estados han logrado reducir la movilidad de las personas y cuántos casos se presentan en sus demarcaciones territoriales, así como para clasificarlos según el riesgo epidemiológico que representan, pero frente a este modelo de señalamiento, no hay una estrategia coordinada, planeada, sostenible y sobre todo sensible a las necesidades de todos los gobernados.

Si en condiciones normales la vigencia de los derechos humanos en México es cuestionable, en un escenario de crisis como el que se vive, la violación a los derechos se agudiza y lo que es peor aún, puede sentirse como justificada, en este contexto los organismos internacionales han advertido:

Las Américas es la región más desigual del planeta, caracterizada por profundas brechas sociales en que la pobreza y la pobreza extrema constituyen un problema transversal a todos los Estados de la región; así como por la falta o precariedad en el acceso al agua potable y al saneamiento; la inseguridad alimentaria, las situaciones de contaminación ambiental y la falta de viviendas o de hábitat adecuado. A lo que se suman altas tasas 
de informalidad laboral $y$ de trabajo e ingresos precarios que afectan a un gran número de personas en la región y que hacen aún más preocupante el impacto socioeconómico del COVID-19. Todo esto dificulta o impide a millones de personas tomar medidas básicas de prevención contra la enfermedad, en particular cuando afecta a grupos en situación de especial vulnerabilidad.

Además, la región se caracteriza por altos índices de violencia generalizada y especialmente violencia por razones de género, de raza o etnia; así como por la persistencia de flagelos tales como la corrupción y la impunidad. Asimismo, en la región prevalece por parte de los ciudadanos y ciudadanas el ejercicio del derecho a la protesta social, en un contexto de represión mediante el uso desproporcionado de la fuerza, así como de actos de violencia y vandalismo; graves crisis penitenciarias que afectan a la gran mayoría de los países; y la profundamente preocupante extensión del fenómeno de la migración, del desplazamiento forzado interno, de personas refugiadas y apátridas; así como la discriminación estructural en contra de grupos en situación de especial vulnerabilidad (CIDH, 2020).

En efecto, las carencias potencian la propagación de las enfermedades o hacen más vulnerables frente a sus efectos a las personas en situación de pobreza, ya que por una parte, no cuentan con las condiciones que faciliten su higiene $\mathrm{e}^{5}$ y un espacio amplio de convivencia, carecen de seguridad social que les permita acudir a recibir atención médica en caso de ser necesario, y por otro lado, sus ingresos se pueden ver seriamente afectados, tanto por si su fuente de trabajo se ve amenazada por las restricciones que impone el gobierno a las empresas, generando ciclos económicos desfavorables, como si se dedican a la actividad informal y sus ingresos se ven mermados debido a la ausencia de clientes para su actividad.

En un estudio descriptivo del Centro Regional de Investigaciones Multidisciplinaria de la Universidad Nacional Autónoma de México (Hernández, 2020) se obtuvo que el $71 \%$ de las víctimas fatales de COVID-19 son personas con escolaridad de primaria o inferior, es decir, primaria trunca, preescolar o sin escolaridad, y aunque se trata de resultados preliminares, apuntan a una tendencia en términos de la vulnerabilidad que padece un gran sector de la población.

Por otra parte, el Estado tiene la obligación de respetar derechos fundamentales no solamente a los mexicanos, sino a toda persona que se encuentre en su territorio y en este sentido, es condenable que se hayan abandonado a centenares de personas migrantes hondureños en la frontera del Ceibo para que cruzaran por sus propios medios y de manera irregular hacia Guatemala, tomando en consideración que es país había cerrado sus fronteras el 16 de marzo (WOLA, 2020).

La situación de confinamiento es una estrategia eficaz si al mismo tiempo se garantizan a la población sus derechos, los derechos tanto civiles y políticos, como los

\footnotetext{
${ }^{5}$ Por el acceso al agua, a viviendas dignas y a recursos para adquirir el material de limpieza personal y doméstico necesario para hacer frente a una enfermedad infecciosa como lo es el COVID19.
} 
económicos, sociales y culturales, es imposible exigir a las personas que se resguarden si no se les dan opciones para no cerrar las empresas, para mantener un nivel de subsistencia digno y la garantía de estar informados de forma oportuna, veraz y bajo criterios de cientificidad.

Si se tiene presente el artículo $1^{0}$ de la Constitución Política de los Estados Unidos Mexicanos que prevé:

En los Estados Unidos Mexicanos todas las personas gozarán de los derechos humanos reconocidos en esta Constitución y en los tratados internacionales de los que el Estado Mexicano sea parte, así como de las garantías para su protección, cuyo ejercicio no podrá restringirse ni suspenderse, salvo en los casos y bajo las condiciones que esta Constitución establece.

Las normas relativas a los derechos humanos se interpretarán de conformidad con esta Constitución y con los tratados internacionales de la materia favoreciendo en todo tiempo a las personas la protección más amplia. Todas las autoridades, en el ámbito de sus competencias, tienen la obligación de promover, respetar, proteger y garantizar los derechos humanos de conformidad con los principios de universalidad, interdependencia, indivisibilidad y progresividad. En consecuencia, el Estado deberá prevenir, investigar, sancionar y reparar las violaciones a los derechos humanos, en los términos que establezca la ley.

En esta concepción amplia de los sujetos obligados y del ámbito extendido de los derechos humanos, no es suficiente con la buena voluntad del Estado de dictar medidas para la protección de la salud, con esta emergencia sanitaria ha quedado en evidencia que la interdependencia de los derechos es indiscutible y que cuando se le pretende fragmentar simplemente no se hacen efectivos y terminan violándose los derechos involucrados.

Con esto se quiere expresar que, solamente por referirnos a un ejemplo, como ya se dijo antes, las relaciones laborales se trastocan si no se reconoce una condición jurídica que posibilite un ambiente económico favorable para la subsistencia de la fuente de trabajo y aunque este y sus prestaciones tendrían que garantizarlos las empresas, la realidad es que una situación como esta, sin precedentes, puede dejar sin liquidez y asfixiar a un sector económico importante en México y provocar el despido masivo y por tanto el desempleo de millones de personas, lo cual es grave no sólo porque el Estado no va a otorgar un mínimo vital a los desempleados al menos durante la pandemia, sino porque además el cierre de empresas significa una recaudación de contribuciones menor lo que redunda en insuficiencia presupuestaria.

De este modo, solo por tener en mente una de tantas situaciones que revelan la interdependencia e indivisibilidad de los derechos, se muestra la necesidad de que los estados, respeten los derechos humanos, diseñen políticas públicas y estrategias orientadas siempre a ampliar los derechos para todos y no a restringirlos, el Estado restringe derechos humanos cuando es incapaz de tener esa visión de interdependencia. 
De acuerdo con Hernández Barrón (2020), el mínimo vital se ve violentado en virtud de una afectación de la cual no se ignora la motivación para llevarla a cabo:

En efecto, el poder Ejecutivo tuvo que tomar medidas para identificar aquellas actividades económicas que se consideraban esenciales en este contexto y que podían seguir operando, frente aquellas que no gozaban con dichos criterios. El problema toma relevancia, pues estas medidas son el resultado de ponderaciones entre diversos principios constitucionales, donde es de suma importancia el grado de justificación que se empleó para llegar a sostener dichas decisiones, ya que estas afectan la dignidad humana $y$, con ello, al derecho humano al mínimo vital.

Enseguida se presenta una tabla en la que se observa de forma sintetizada los efectos de las medidas adoptadas y los derechos humanos que se ven afectados por ellas:

\section{Cuadro 1. Medidas adoptadas por el gobierno mexicano ante el COVID-19}

\begin{tabular}{|c|c|c|c|}
\hline Medida adoptada & Destinatarios & Consecuencia & $\begin{array}{l}\text { Derecho humano } \\
\text { afectado }\end{array}$ \\
\hline $\begin{array}{c}\text { Suspensión temporal } \\
\text { de las relaciones de } \\
\text { trabajo }\end{array}$ & $\begin{array}{c}\text { Empresas que no } \\
\text { desempeñan } \\
\text { actividades esenciales }\end{array}$ & $\begin{array}{l}\text { Despido masivo/ } \\
\text { desempleo }\end{array}$ & $\begin{array}{l}\text { Estabilidad en el } \\
\text { empleo, nivel de } \\
\text { vida adecuado }\end{array}$ \\
\hline $\begin{array}{l}\text { No otorgamiento de } \\
\text { beneficios fiscales }\end{array}$ & $\begin{array}{l}\text { Todas las personas } \\
\text { que generan ingresos }\end{array}$ & $\begin{array}{l}\text { Cierre de empresas/ } \\
\text { no recaudación }\end{array}$ & $\begin{array}{l}\text { Principio de equidad } \\
\text { y proporcionalidad }\end{array}$ \\
\hline $\begin{array}{c}\text { No realización de } \\
\text { determinadas } \\
\text { actividades comerciales }\end{array}$ & $\begin{array}{l}\text { Empresas que se } \\
\text { consideran no } \\
\text { esenciales }\end{array}$ & $\begin{array}{l}\text { No generación de } \\
\text { recursos económicos }\end{array}$ & $\begin{array}{c}\text { Libertad para } \\
\text { desempeñar } \\
\text { actividades lícitas }\end{array}$ \\
\hline Suspensión de labores & $\begin{array}{l}\text { Personas consideradas } \\
\text { vulnerables }\end{array}$ & $\begin{array}{c}\text { Disminución de } \\
\text { condiciones laborales } \\
\text { /falta de productividad }\end{array}$ & $\begin{array}{l}\text { Libertad de trabajo, } \\
\text { nivel de vida adecuado }\end{array}$ \\
\hline $\begin{array}{l}\text { Suspensión de clases } \\
\text { presenciales }\end{array}$ & $\begin{array}{l}\text { Personal administrativo, } \\
\text { docente y alumnos }\end{array}$ & $\begin{array}{l}\text { Cierre de escuelas } \\
\text { /afectación en el } \\
\text { desarrollo de los } \\
\quad \text { estudiantes }\end{array}$ & $\begin{array}{l}\text { Derecho a la educación, } \\
\text { cultura, deporte, salud } \\
\text { libertad de despeñar } \\
\text { actividades lícitas }\end{array}$ \\
\hline $\begin{array}{c}\text { No realizar actividades } \\
\text { que impliquen } \\
\text { concentración de } \\
\text { personas }\end{array}$ & Todas las personas & $\begin{array}{l}\text { Afectación en la } \\
\text { salud, bienestar }\end{array}$ & $\begin{array}{l}\text { Derecho a la } \\
\text { recreación, reunión }\end{array}$ \\
\hline $\begin{array}{c}\text { No realizar actividades } \\
\text { de tránsito o } \\
\text { desplazamiento }\end{array}$ & Toda la población & $\begin{array}{l}\text { Afectación en la } \\
\text { esfera laboral, social } \\
\text { y personal }\end{array}$ & $\begin{array}{l}\text { Libertad de tránsito, } \\
\text { residencia, derecho a la } \\
\text { salud, seguridad física }\end{array}$ \\
\hline
\end{tabular}

Fuente: Elaboración propia con datos derivados de los Acuerdos emitidos por diversas autoridades para la adopción de medidas para mitigar los efectos de la pandemia ocasionada por COVID-19. 


\section{LA REPARACIÓN DE DAÑOS POR RESTRICCIÓN O SUSPENSIÓN DE LOS DERECHOS HUMANOS}

Entre las medidas que se han adoptado la principal ha sido el confinamiento, a través del cual se obliga a las personas a permanecer en sus casas, limitando su libertad de tránsito, pues se les vigila por la propia autoridad y se sanciona el incumplimiento con multas o arrestos; algunos países establecieron el cierre de fronteras negando la entrada o salida de personas al territorio estatal, o en su caso, el sometimiento a revisiones y exámenes médicos que garanticen el buen estado de salud de la persona que ingresa en el territorio; en atención a la población existente en las comunidades o ciudades se determinó la imposibilidad de apertura de comercios y la prohibición de realización de actividades productivas, impidiendo con ello el ejercicio del derecho a la libertad para dedicarse a realizar actividades lícitas; y finalmente en atención a la posibilidad de contagio por la concentración de personas y la cercanía en que éstas se encuentran, se determinó la prohibición de apertura de las escuelas, centros culturales o deportivos, afectando el derecho a la educación, cultura y deporte.

Todo ello ha afectado de manera automática alguno de los derechos humanos reconocidos por los Estados como la seguridad, libertad, integridad física, información o el buen vivir, causando daños materiales e inmateriales a sus titulares, por lo que cabe preguntarse si los individuos deberán de acatar las medidas que dicten sus gobiernos y soportar los daños por existir una justificación (la protección del derecho a la salud de todos), o existe algún parámetro que regule la actuación de los Estados al adoptar las medidas mencionadas que permita que se dé una reparación del daño.

\section{ELEMENTOS PARA DETERMINAR UNA RESPONSABILIDAD DEL ESTADO POR VIOLACIÓN A LOS DERECHOS HUMANOS}

La posibilidad de responsabilidad de los Estados derivada de las medidas adoptadas por sus gobiernos para atender la problemática generada por el COVID-19, debe ser determinada a través de las normas que a nivel internacional han sido dictadas para regular su actuación y en ciertos casos permitir la restricción y suspensión de los derechos humanos de sus gobernados con base al orden constitucional existente en cada uno de ellos. Para los fines de la presente investigación, se realizará un análisis breve sólo de algunas disposiciones que podrían servir de parámetro en la actuación de los Estados al generar disposiciones normativas encaminadas a mitigar los efectos de la pandemia.

En el Sistema Universal de Derechos Humanos, la Comisión de Derecho Internacional de las Naciones Unidas adoptó en su $53^{\circ}$ periodo de sesiones y fue aceptado por la Asamblea General en su resolución 53/83 del 12 de diciembre del 2001, un Proyecto de artículos sobre responsabilidad del Estado por hechos internacionalmente ilícitos que permiten tener un parámetro de actuación de estos, a fin de estable- 
cer en qué casos podría considerarse la existencia de un hecho internacionalmente ilícito que genere la responsabilidad (Asamblea General de las Naciones Unidas, 2001).

En dicho proyecto se establecen como requisitos para la existencia de un hecho internacionalmente ilícito de un Estado, cualquier acción u omisión que se pueda atribuir al Estado en relación con la normativa internacional, que genere una violación a una obligación asumida; así mismo se deja claro que la conducta puede ser realizada por cualquier órgano del Estado sin importar el tipo de función que desempeñe, por personas u órganos que no pertenecen al Estado pero facultados por este para realizar atribuciones de poder público, o en casos de órganos que son puestos a su disposición por otro Estado.

Así mismo el proyecto regula excluyentes de responsabilidad de hechos internacionalmente ilícitos como la fuerza mayor, entendida como una fuerza irresistible o un acontecimiento imprevisto ajeno al control del Estado que impida cumplir con su obligación; el peligro extremo, que permite a los Estados adoptar medidas para salvar la vida de personas confiadas a su cuidado; o el estado de necesidad, cuando las medidas sean el único modo de salvaguardar un interés esencial de un peligro grave e inminente y no se afecte de manera grave el interés esencial del Estado o de otros Estados.

A nivel regional y en específico para el tema analizado en esta investigación, el Sistema Interamericano de Derechos Humanos contempla en el artículo $27^{\circ}$ de la Convención Americana sobre derechos Humanos, que los Estados parte puedan llevar a cabo la suspensión de las obligaciones contraídas en la Convención, cuando exista guerra, peligro público o cualquier emergencia que afecte la independencia o seguridad del Estado, pero siempre que sea por un tiempo limitado y no se afecten otras normas de carácter internacional, ni se provoque ningún tipo de discriminación por motivo de raza, color, sexo, idioma, religión u origen social; esta medida no es absoluta pues existe impedimento para suspender ciertos derechos y las garantías judiciales de los mismos 6 .

De conformidad con dicho precepto, para que una afectación de derechos en un periodo de excepción sea válida, la Comisión Interamericana de Derechos Humanos ha determinado que debe de reunir dos requisitos de forma: la proclamación consistente en comunicar de manera interna a los gobernados el sentido de la suspensión, y la notificación, que implica avisar a los demás miembros de la Convención quienes podrán revisar que no exista un abuso de las facultades de suspensión por el Estado que la decreta, para dejar de observar sus obligaciones (Tórtora Aravena, 2010, pp.171-173).

Otro aspecto que es importante considerar es el relativo a los daños que se pueden llegar a causar entre particulares derivados de las medidas adoptadas por los

\footnotetext{
${ }^{6}$ Los derechos no sujetos de suspensión por la Convención Americana sobre Derechos Humanos son los relativos a la personalidad jurídica, vida, integridad personal, prohibición de la esclavitud y servidumbre, principio de legalidad y de retroactividad, libertad de conciencia y de religión, protección a la familia, derecho al nombre, derechos del niño, derecho a la Nacionalidad y derechos políticos.
} 
Estados, pues la Corte Interamericana de Derechos Humanos ha señalado que, si bien es cierto que el Estado no es responsable de cualquier violación a derechos humanos cometida entre particulares, si se le puede atribuir responsabilidad cuando las autoridades sabían o debían haber sabido que existían un riesgo real e inmediato para la vida y/o integridad persona de un individuo o grupo, y no adoptaron las medidas que dentro de sus atribuciones pudieron haber prevenido o evitado el riesgo (Corte Interamericana de Derechos Humanos, 2017).

Con las medidas adoptadas por los Estados, hay una gran probabilidad de que los particulares cometan actos de afectación de derechos entre sí, en la búsqueda de protección de sus intereses personales y el Estado podría caer en el supuesto de ser responsable; un ejemplo simple se encuentra en los establecimientos que siguen prestando servicio, donde el propietario como particular puede causar daño a sus trabajadores y a las personas que acuden al recibir el servicio, exponiéndolos al contagio, cuando no se cumplen los protocolos emitidos para tal efecto, y las autoridades no desempeñan su deber de verificación de la implementación de los mismos.

Además de lo anterior, el 10 de abril de 2020 la Comisión Interamericana de Derechos emitió la resolución número 1/20 que denominó "Pandemia y derechos humanos en las Américas" con la finalidad de que las medidas que adopten los Estados tengan como centro el pleno respeto de los derechos humanos; dentro de dicha resolución se aborda un apartado específico con relación a los estados de excepción, restricción a las libertades fundamentales y Estado de Derecho, donde se reitera lo contemplado por el artículo 27 de la Convención Americana sobre Derechos Humanos, pero además se desprenden otros lineamientos, siendo trascendentes para los fines de esta investigación los siguientes (Comisión Interamericana de Derechos Humanos, 2020):

a) Se debe asegurar que cualquier restricción o suspensión se sustente en evidencia científica, considerando los efectos que traerá en los grupos vulnerables?.

b) Establecer medios de control de las disposiciones dictadas, debiendo evaluar de manera periódica la necesidad de mantenerlas vigentes.

c) Abstenerse de restringir el trabajo y circulación de periodistas y personas defensoras de derechos humanos que cumplen una función de informar y monitorear las acciones del Estado, garantizando que estas últimas no serán sujetas de procedimiento por las opiniones que emiten, ni exponerlas a ataques físicos y virtuales.

d) Abstenerse de bloquear sitios de medios de comunicación, plataformas o cuentas en Internet, garantizando el acceso al servicio de Internet, debiendo además dictar medidas para reducir la brecha digital de los grupos vulnerables.

\footnotetext{
${ }^{7}$ En la parte considerativa de la resolución la Comisión Interamericana de Derechos Humanos considera como grupos vulnerables a las personas mayores, personas de cualquier edad con afecciones médicas preexistentes, personas privadas de libertad, mujeres, pueblos indígenas, personas en situación de movilidad humana, niñas, niños y adolescentes, personas LGBTI, personas afrodescendientes, personas con discapacidad, personas trabajadoras, y personas que viven en pobreza y pobreza extrema, personas trabajadoras informales y personas en situación de calle, defensoras y defensores de derechos humanos, líderes sociales, profesionales de la salud y periodistas.
} 
a) Se debe asegurar que cualquier restricción o suspensión se sustente en evidencia científica, considerando los efectos que traerá en los grupos vulnerables?.

b) Establecer medios de control de las disposiciones dictadas, debiendo evaluar de manera periódica la necesidad de mantenerlas vigentes.

c) Abstenerse de restringir el trabajo y circulación de periodistas y personas defensoras de derechos humanos que cumplen una función de informar y monitorear las acciones del Estado, garantizando que estas últimas no serán sujetas de procedimiento por las opiniones que emiten, ni exponerlas a ataques físicos y virtuales.

d) Abstenerse de bloquear sitios de medios de comunicación, plataformas o cuentas en Internet, garantizando el acceso al servicio de Internet, debiendo además dictar medidas para reducir la brecha digital de los grupos vulnerables. e) Asegurar el acceso a la información pública, dando prioridad a las solicitudes relativas a la emergencia de salud pública.

f) Los pronunciamientos y declaraciones de funcionarios deben realizarse con diligencia y con bases científicas, buscando combatir la desinformación que se circula a través de Internet.

g) Proteger el derecho a la privacidad y los datos personales de la población y en especial de los pacientes y personas sujetas a exámenes médicos, debiendo solo almacenar los datos durante la pandemia.

h) En caso de utilizar herramientas de vigilancia digital, deberán de transparentarse y serán limitadas en cuanto a su propósito y tiempo.

i) Garantizar la no realización de detenciones arbitrarias y toda detención debe contar con control judicial.

Los lineamientos anteriores también constituyen un parámetro internacional a considerar para evaluar la posibilidad de una responsabilidad de los Estados, pues amplían los requisitos señalados en la Convención Americana sobre Derechos Humanos para llevar a cabo la suspensión o restricción de derechos humanos, constituyendo una omisión en términos de responsabilidad internacional la falta de acatamiento de los mismos por parte de los Estados.

Por lo que se refiere al orden interno mexicano, en materia del derecho a la salud, el artículo 73 fracción XVI de la Constitución Política de los Estados Unidos Mexicanos establece la facultad del Congreso para emitir leyes en materia de salubridad general, pero dicho precepto reconoce la figura del Consejo de Salubridad General, el cual actúa como un órgano colegiado en materia sanitaria que depende del Presidente de la República, realizando funciones normativas, consultivas y ejecutivas que tienen carácter general y obligatorio en todo el territorio mexicano; además en la misma fracción se establece la facultad de la Secretaría de Salud para dictar medidas preventivas en caso de epidemias graves o peligro de invasión de enfermedades exóticas en el país, las cuales deberán ser sancionadas por el Presidente de la República.

Así mismo de manera general la misma Constitución establece restricción de derechos humanos y sus garantías en el artículo 29, siempre y cuando se cumplan los siguientes requisitos: 1) es una facultad del Presidente de la República con aprobación 
del Congreso o Comisión Permanente, en su caso; 2) se puede decretar en todo el país o en un lugar determinado; 3) solo es temporal; 4) se debe realizar por medio de prevenciones generales; 5) no se dirige a persona determinada; 6) existen derechos cuyo ejercicio no puede restringirse ni suspenderse ${ }^{8}$; 7) debe existir fundamentación y motivación para la restricción y suspensión y existir proporcionalidad al peligro existente con base en los principios de legalidad, racionalidad, proclamación, publicidad y no discriminación; 8) los decretos expedidos para la suspensión o restricción deben ser revisados por la Suprema Corte de Justicia de la Nación a fin de establecer su constitucionalidad y validez; 9) al darse el fin de la restricción o suspensión, las medidas adoptadas quedarán sin efecto (Olalde Vieyra, 2017, pp. 283-285).

La propia Suprema Corte de Justicia en México ha dejado claro que ningún derecho fundamental es absoluto por lo que pueden estar sujetos a restricciones; en caso de que el legislador sea quien establezca las restricciones deberá cumplir con tres requisitos: 1) estar permitida dentro del texto constitucional; 2) ser idónea por no existir otro medio para la obtención del fin; 3) ser proporcional al haber correspondencia entre el fin buscado y las afectaciones que se produzcan en otros derechos; además será un Juez quien realice un control de la medida legislativa según la normativa nacional e internacional en materia de derechos humanos (Suprema Corte de Justicia de la Nación, 2012b).

Como puede verse, existe un campo amplio de parámetros normativos internacionales y nacionales que regulan la actuación de los Estados para proteger los derechos humanos, y que, en el caso de México, establecen los lineamientos a seguir por las autoridades para poder llevar a cabo la suspensión o restricción de derechos, derivado de las políticas públicas adoptadas para contrarrestar los efectos de la pandemia generada por el coronavirus (COVID-19), los cuales permitirán determinar en qué casos la actuación del Estado produce un hecho ilícito que da lugar a la reparación de los daños.

\section{FORMAS DE REPARACIÓN DE LOS DAÑOS CAUSADOS POR VIOLACIÓN DE DERECHOS HUMANOS}

Ante la responsabilidad que tienen los Estados de buscar el respeto y protección de los derechos humanos de sus connacionales, surge el derecho de los particulares a obtener la reparación de los daños que pudieran causarse derivados del incumplimiento; este derecho puede adoptar diversas formas que tienen como fundamento el derecho que se lesiona, las circunstancias en que se cometió, permitiendo no solo la restitución a la situación anterior, sino también una compensación en aquellos casos que es imposible lo anterior.

\footnotetext{
${ }_{8}^{8}$ Derechos a la no discriminación, al reconocimiento de la personalidad jurídica, a la vida, a la integridad personal, a la protección a la familia, al nombre, a la nacionalidad; los derechos de la niñez; los derechos políticos; las libertades de pensamiento, conciencia y de profesar creencia religiosa alguna; el principio de legalidad y retroactividad; la prohibición de la pena de muerte; la prohibición de la esclavitud y la servidumbre; la prohibición de la desaparición forzada y la tortura; ni las garantías judiciales indispensables para la protección de tales derechos.
} 
Con base en el Proyecto de artículos sobre responsabilidad del Estado por hechos internacionalmente ilícitos ya comentado (Asamblea General de las Naciones Unidas, 2001), se reconoce el derecho a la reparación que debe realizar un Estado que sea responsable por un hecho internacionalmente ilícito, determinando que dicha reparación se puede dar tanto en el aspecto material como en el moral.

Así mismo dicho proyecto establece de manera expresa la irrelevancia de las normas internas del Estado responsable para llevar a cabo la reparación del daño, pues no se consideran una justificación para con cumplir con esa obligación a su cargo.

Finalmente, el proyecto contempla como formas de reparación de daños a la restitución, misma que busca reestablecer la situación existente antes de la comisión del ilícito; en caso de ser imposible ello, se deberá cubrir una indemnización la cual inclusive podrá generar intereses desde la fecha en que debió de cubrirse, hasta su liquidación; y en ciertos casos, podrá determinarse la satisfacción, que consiste en un reconocimiento de la violación, expresión de pesar, una disculpa formal, cualquier forma semejante.

Por otro lado en el Sistema Interamericano la aplicación del artículo 63.1 de la Convención Americana de Derechos Humanos y su interpretación a través de las resoluciones emitidas por la Corte Interamericana, ha generado el concepto de reparación integral del daño; este concepto permite que se otorguen medidas como investigación, restitución, rehabilitación, actos en beneficio de las víctimas, garantías de no repetición de violaciones, e indemnización compensatoria (Calderón Gamboa, 2013, p. 11).

En el caso de México, nuestro máximo tribunal no ha sido ajeno al tema y derivado de la adhesión de México a la Convención Americana sobre Derechos Humanos y el reconocimiento de la competencia de la Corte Interamericana, ha dejado claro que las sentencias que sean emitidas en los asuntos en que el Estado mexicano sea parte, son obligatorias en todo su contenido, incluyendo sus criterios interpretativos (Suprema Corte de Justicia de la Nación, 2012a), por lo que se ha reconocido que el resarcimiento de un daño causado es un derecho fundamental que se vuelve operativo cuando la actuación del Estado se lleva a cabo de manera ilícita, debiendo buscar los mecanismos que permitan anular las consecuencias generadas volviendo las cosas al estado en que se encontraban, y ante su imposibilidad, generar una compensación económica justa según las circunstancias de cada caso (Suprema Corte de Justicia de la Nación, 2017).

La situación generada a través de las medidas adoptadas por el gobierno mexicano para contrarrestar los efectos por coronavirus (COVID-19) en su población podría generar costos muy altos para el Estado, pues ante la falta de una planeación adecuada por parte de las autoridades para establecer políticas públicas eficientes y eficaces, se han causado afectaciones en los derechos de los gobernados, que basándose en los parámetros ya establecidos, permitirían demandas de reconocimiento de responsabilidad que se traducirían en el pago de cantidades de dinero a través de la 
figura de la indemnización, por tratarse de afectaciones materiales que es imposible desaparecer volviendo las cosas al estado en que se encontraban antes de la emisión, e inmateriales en cuyo caso el pago hace las veces de una compensación.

\section{MECANISMOS INTERNOS E INTERNACIONALES PARA LOGRAR UNA REPARACIÓN INTEGRAL DE LOS DAÑOS CAUSADOS}

Las imágenes que los medios de comunicación han presentado relacionadas con las medidas tomadas por las autoridades para contrarrestar los efectos del coronavirus (COVID-19), dejan ver un panorama de descontento en la población ante la privación de sus derechos y en muchas ocasiones, hacen patente la falta de orden en la ejecución de estas a través de los funcionarios públicos, generando una presunción de responsabilidad y de existencia de daños en la persona y patrimonio de los gobernados; para poder determinar si existen mecanismos internos de protección contra estas afectaciones, es indispensable atender a su naturaleza pues algunos Estados solo contemplan mecanismos internos de responsabilidad, en atención al tipo de acto u omisión que se les atribuye.

En ese sentido, uno de esos estados que limita su responsabilidad es México en donde la figura de la responsabilidad patrimonial contemplada por el último párrafo del artículo 109 de la Constitución establece su procedencia solo en caso de actuaciones administrativas irregulares, entendiendo por estas, aquellas que causan un daño que los particulares no tenían el deber jurídico de soportar, quedando excluidas con base en ello quedan las actuaciones legislativas y jurisdiccionales; las medidas adoptadas por el gobierno mexicano para impedir la propagación del coronavirus (COVID-19) se podrían ubicar en el supuesto de ser actos administrativos y por ello los daños generados con las mismas podrían reclamarse en la vía administrativa mediante un juicio contencioso.

Otro mecanismo interno para obtener el resarcimiento de daños causados por violación a derechos humanos derivados de las medidas adoptadas por la pandemia, podría ser el Juicio de Amparo; como mecanismo de defensa puede servir para proteger la libertad personal, combatir leyes inconstitucionales, como un medio de impugnación de sentencias judiciales o para reclamar actos y resoluciones de la administración activa (Fix-Zamudio \& Valencia Carmona, 2012, p. 994); se comenta que podría operar como mecanismo de resarcimiento, ya que solo sería así cuando no sea posible aplicar la restitución como medida.

Esta posibilidad deriva de la necesidad de dar cumplimiento a las sentencias en que se reconoce la violación de un derecho humano y por alguna circunstancia no es posible regresar las cosas al estado en que se encontraban antes de la actuación de la autoridad.

Para tal efecto la Ley de Amparo contempla un procedimiento denominado 
incidente de cumplimiento sustituto, el cual busca tener por cumplida una sentencia dictada dentro del Juicio de Amparo a través del pago de los daños y perjuicios causados al gobernado, en aquellos casos en que no sea posible ejecutar la sentencia, pues ello generaría una afectación grave a la sociedad, en ponderación con los beneficios que podría obtener el quejoso, o cuando las por las circunstancias propias del caso concreto, sea materialmente imposible restituir las cosas al estado en que se encontraban, o en caso de poderlo hacer, sea muy gravoso para el gobernando.

En el ámbito internacional y únicamente de manera subsidiaria ante la imposibilidad de lograr el resarcimiento de daños con los mecanismos internos, se podría presentar una queja o denuncia ante la Comisión Interamericana de Derechos Humanos, pero este mecanismo exclusivamente va encaminado a realizar una investigación para lograr un acuerdo entre las partes que podría incluir el resarcimiento de los daños, ya que no se obtiene una resolución de condena al pago de una indemnización por la afectación a los derechos humanos; para ello el mecanismo ideal sería presentar una demanda ante la Corte Interamericana de Derechos Humanos acreditando las violaciones a los derechos y libertades consagradas en la Convención Americana sobre Derechos Humanos y obtener una resolución definitiva que declare responsabilidad del Estado y obligue al resarcimiento de los daños causados.

\section{REFLEXIONES FINALES}

Las acciones y omisiones del Estado mexicano frente a la pandemia por COVID-19 han dejado en evidencia que la realización de los derechos humanos es más frágil de lo que se sabía y que su violación se exacerba por la incapacidad de articular una adecuada estrategia para contener y mitigar los estragos que ha dejado y seguirá generando, no solamente en el ámbito de la salud, sino en todo lo que se trastoca. Es obvio que la interdependencia de los derechos se hace patente tanto para la vigencia como para su violación, no se puede garantizar salud, ni empleo, ni libertades, ni desarrollo, ni educación si no hay una política fuerte y consolidada de respeto a los derechos humanos.

Por ello resulta de suma importancia que los gobiernos tengan presente la importancia de velar por el respeto de los derechos humanos en las medidas que se adopten a través de sus políticas públicas, la cuales deben de ir de la mano de los parámetros internos e internacionales que se han dictado al respecto, en donde su obligación tiene como base no sólo un hacer o no hacer de sus órganos, sino también el hacer o no hacer de los particulares de los que se sirva para los fines públicos.

Frente a este escenario el Estado debe asumir responsabilidades para evitar que las violaciones se sigan perpetrando en el futuro; la ejemplaridad que entrañan las consecuencias de este desastre sanitario, económico y social tiene que ser un punto de inflexión sobre el cual el Estado mexicano no vuelva a transitar. 


\section{REFERENCIAS}

1. Asamblea General de las Naciones Unidas. (2001). 56/83. Responsabilidad del Estado por hechos internacionalmente ilícitos (A/RES/56/83).

2. Calderón Gamboa, J. F. (2013). La evolución de la reparación integral en la jurisprudencia de la Corte Interamericana de Derechos Humanos (Primera). Comisión Nacional de Derecho Humanos.

3. Comisión Interamericana de Derechos Humanos. (CIDH) (2020). Pandemia y Derechos Humanos en las Américas (Resolución No. 1/2020).

4. Corte Interamericana de Derechos Humanos. (2017). Caso Gutiérrez Hernández y otros Vs. Guatemala. Excepciones Preliminares, Fondo, Reparaciones y Costas. (Serie C No. 339, Párrafo 140).

5. Diario Oficial de la Federación (2020). Acuerdo de 39-14/2020 emitido por el Pleno del Consejo de la Judicatura de la Ciudad de México. Ciudad de México, México

6. Diario Oficial de la Federación (2020). Acuerdo del 23 de marzo del 2020. Consejo General de Salubridad reconoce la epidemia de enfermedad por el virus Covid-19 en México como una enfermedad grave de atención prioritaria, por ello se establecen las actividades de preparación y respuesta ante dicha pandemia. Ciudad de México, México.

7. Diario Oficial de la Federación (2020). Acuerdo del 24 de marzo del 2020 emitido por la Secretaría de Salud, establece las medidas preventivas que se deberán implementar para la mitigación y control de riesgos para la salud que implica la enfermedad por el virus Covid-19. Ciudad de México, México.

8. Diario Oficial de la Federación (2020). Acuerdo del 26 de marzo del 2020, emitido por la Secretaría de Salud, donde se establece la suspensión de plazos y términos legales en la práctica de actuaciones y diligencias en los procedimientos administrativos que se desarrollan ante la Secretaría de Salud, sus unidades administrativas y organismos desconcentrados (2020). Ciudad de México, México.

9. Diario Oficial de la Federación (2020) Acuerdo del 26 de marzo del 2020, donde el Consejo de Salubridad General señala los días inhábiles del 26 de marzo al 19 de abril de 2020 para la realización de trámites administrativos. Ciudad de México, México.

10. Diario Oficial de la Federación (2020). Decreto emitido por el titular del poder Ejecutivo Federal, por el que se declaran acciones extraordinarias en las regiones afectadas de todo el territorio nacional en materia de salubridad general para combatir la enfermedad de atención prioritaria generada por el virus Covid-19, 27 de marzo de 2020. 
11. Diario Oficial de la Federación (2020). Acuerdo emitido por el Consejo de Salubridad General del 30 de marzo de 2020 por el cual se declara como emergencia sanitaria a la epidemia de enfermedad generada por el virus Covid-19. Ciudad de México, México.

12. Diario Oficial de la Federación (2020). Acuerdo emitido por la Secretaría de Salud el 30 de marzo del 2020, donde se establecen acciones extraordinarias para atender la emergencia sanitaria por causa de fuerza mayor generada por el virus Covid-19. Ciudad de México, México

13. Diario Oficial de la Federación (2020). Acuerdo del 14 de mayo de 2020 por el que se establece una estrategia para la reapertura de las actividades sociales, educativas y económicas, así como un sistema de semáforo por regiones para evaluar semanalmente el riesgo epidemiológico relacionado con la reapertura de actividades en cada entidad federativa, así como se establecen acciones extraordinarias. Ciudad de México, México.

14. Fix-Zamudio, H., \& Valencia Carmona, S. (2012). Derecho Constitucional mexicano y comparado. Porrúa.

15. Instituto Nacional de Geografía, Estadística e Informática (INEGI) (2020). Encuesta Nacional de Ocupación y Empleo de abril 2020.

16. Hernández Barrón, Alfonso (2020). El mínimo vital en contextos de crisis sanitarias; ponderación y umbrales de justificación: Un análisis a raíz del Acuerdo por el que se establecen acciones extraordinarias para la emergencia sanitaria generada por el virus Sars-cov2 (Covid-19) emitido por la Secretaría de Salud en México, en Derechos Fundamentales a Debate, Latindex y Comisión Estatal de Derechos Humanos Jalisco, No. 12 enero-abril, pp. 12-32.

17. Hernández Bringas, Héctor Hiram (2020). Mortalidad por COVID19 en México. Notas preliminares para un perfil sociodemográfico. Notas de coyuntura del CRIM núm. 36, junio 2020. https://web.crim.unam.mx/sites/default/files/2020-06/crim_036_ hector-hernandez_mortalidad-por-covid-19_0.pdf

18. Ley Federal del Trabajo (2019). Diario Oficial de la Federación, Ciudad de México, México, 02 de julio de 2019.

19. Ley General de Salud. (2019). Diario Oficial de la Federación, Ciudad de México, México, 29 de noviembre de 2019.

\section{México (2020). Covid-19 México. https://coronavirus.gob.mx/datos/}

21. Olalde Vieyra, J. A. (2017). Limitaciones, restricciones y suspensión de derechos humanos y sus garantías en la Constitución Política de los Estados Unidos Mexicanos y los tratados internacionales. Revista de la Facultad de Derecho de México, 65(263), 275. https://doi.org/10.22201/fder.24488933e.2015.263.59828 
22. Organización Mundial de la Salud (OMS) (2020). Declaración sobre la segunda reunión del Comité de Emergencias del Reglamento Sanitario 『Internacional (2005) acerca del brote del nuevo coronavirus (2019-nCoV). https://www.who.int/es/news -room/detail/30-01-2020-statement-on-the-second-meeting-of-the-internationalhealth-regulations-(2005)-emergency-committee-regarding-the-outbreak-of-novelcoronavirus-(2019-ncov)

23. Organización Panamericana de la Salud (OPS) (2020). La OMS caracteriza a COVID-19 como una pandemia. https://www.paho.org/hq/index.php?option=com_content\&view=article\&id=15756:who-characterizes-covid-19-as-a-pandemic\&Itemid $=1926 \&$ lang $=$ es

24. Suprema Corte de Justicia de la Nación. (2012a). Corte Interamericana de Derechos Humanos. Efectos de sus sentencias en el ordenamiento jurídico mexicano. (Tesis: 1a. XIII/2012 (10a.)). Seminario Judicial de la Federación y su Gaceta.

25. Suprema Corte de Justicia de la Nación. (2012b). Restricciones a los derechos fundamentales. Elementos. Elementos que el Juez Constitucional debe tomar en cuenta para considerarlas válidas. (Tesis: 1a./J. 2/2012 (9a.)). Seminario Judicial de la Federación y su Gaceta.

26. Suprema Corte de Justicia de la Nación. (2017). Derecho Fundamental a un reparación integral o justa indemnización. Su concepto y alcance. (Tesis: 1a./J. 31/2017 (10a.)). Gaceta del Semanario Judicial de la Federación.

27. Tórtora Aravena, H. (2010). Las limitaciones a los derechos fundamentales. Estudios constitucionales, 8(2), 167-200. https://doi.org/10.4067/s0718-52002010000200007

28. Washington Office on Latin America (WOLA) (2020), Carta al gobierno de México: es imperativo proteger los derechos de personas migrantes durante la pandemia COVID-19, Washington.https://www.wola.org/es/2020/04/carta-gobierno-mexico-derechoshumanos-migrantes-pandemia-covid-19/. 